\title{
Design Optimization and Analysis of Braking System of Go-Kart
}

\author{
Rajkumar M a, Soundar Rajan $\mathrm{M}^{\mathrm{a}}$ \\ B.E Mechanical Engineering \\ Loyola ICAM College of Engineering and Technology \\ (LICET), Chennai, India
}

\author{
Queen Florence Mary ${ }^{\mathrm{b}}$ \\ Head of the Department \\ Department of Mechanical Engineering, \\ Loyola ICAM College of Engineering and Technology \\ (LICET), Chennai, India
}

\begin{abstract}
This title presents the empirical research work on the braking system of Go-kart. A Go-kart is a very small motor vehicle with four wheels, used for racing. Brake system is very essential for the vehicle to reduce the speed or to stop the vehicle. Go-kart is a race vehicle hence its design phase plays a vital role in performance of the kart. In dynamic conditions the forces acting on the vehicle varies with respect to the speed and design parameters, our project aims to study the vehicle dynamics with respect to technical specifications and calculating the forces at various hardpoints of the kart, thereby analysis of the various components of the braking system is done.
\end{abstract}

The brake rotor is the component where the energy transfer takes place, while braking, the kinetic energy is transferred to heat energy by the rotor thus the factor of safety and thermal stability of the brake rotor is important. Hence structural and thermal analysis of the brake rotor is analysed using Ansys (CFD). The driver ergonomics has to be considered while designing, this project aims to provide minimum pedal effort by fixing the optimal pedal ratio. The structural analysis of the brake pedal and brake rotor hub are done using Ansys.

Keywords-Go-kart, Brake Rotor, Load Transfer, Pedal Ratio, Energy distribution equation, Structural Analysis, Thermal Analysis-CFD.

\section{INTRODUCTION}

Go-karting is one of the motor sports, it was quite popular in the United States in the late 1950s. In the later period its popularity spread all over the world. In India, Gokarting is done in many race clubs, amusement parks and there are many karting events organized for the Engineering students like BFKCT - Bharath Formula Karting, International Go-Kart Championship, GKDC (Go kart design challenge) and IKC (Indian karting championship). Some schools are also having Go-kart to encourage the student's activities in motorsports and there are some corporate karting events organized for entertainment purposes. Go-kart is a single seated compact vehicle built for racing and also for entertainment purposes. Our project aims on design optimization of the braking system of Go-kart by considering the various factors like load transfer during dynamic condition, Energy distribution equation, cooling medium and cooling rate of the disc after braking.

A brake is a device by means of which artificial frictional resistance is applied to a moving membrane in order to retard or stop the motion of the vehicle. In the process of braking the brake absorbs the kinetic energy of the vehicle and transforms in the form of heat energy. Then the heat energy is transformed to the atmosphere by convective heat transfer. The main requirement of the braking system is to stop the vehicle at minimum distance after applying the brake, theoretical calculations are done and the stopping distance, temperature rise in disc and stopping time are calculated. The theoretical results go hand in hand with the practical results.

In order to select the best braking system for Go-kart, basic research work is done on types of braking system and hydraulic brake is selected, since it is very effective compared to drum brake and it reduces the design complexity and helps to reduce the overall weight of the kart.

\section{TECHNICAL SPECIFICATIONS}

The manufactured kart is taken for the study, following are the technical specification of the kart.

A. Overall dimensions

TABLE I. DESIGN CONDITION OF THE KART

\begin{tabular}{|l|l|}
\hline Wheel base, $\mathrm{L}$ & $1.22 \mathrm{~m}$ \\
\hline Centre of Gravity height, $\mathrm{h}$ & $0.259 \mathrm{~m}$ \\
\hline Total Weight, W & $180 \mathrm{~kg}$ \\
\hline Ground Clearance & 1.5 inch \\
\hline
\end{tabular}

B. Brake System

Braking system of our vehicle was designed to achieve maximum braking efficiency and to provide greater vehicle safety.

\section{Brake Pedal}

Passengers cars generally use a pedal ratio between 4 to 7 . A pedal ratio of 7:1 is selected for our kart.

\section{Master cylinder}

Analysing the available Original Equipment Manufacturer, we chose master cylinder of TVS APACHE RTR 160. Since, it has a tandem cylinder, which gives higher pressure to the brake fluid. The piston diameter of this master cylinder is $19.15 \mathrm{~mm}$

\section{E. Brake Caliper}

We chose TVS APACHE RTR 160 double piston, floating caliper. ${ }^{[1]}$ Since the caliper has two pistons, the rubbing surface of the brake pad over the disc will be greater and the floating caliper applies the friction force on both sides 
of the brake disc. Hence, it is more effective than a fixed caliper.

\section{F. Brake Disc}

The best geometry and material for the disc is selected by considering the following.

Design factors to be considered for brake rotor include

- Brake disc diameter

- Brake disc material

- Weight of brake disc

- Thickness of brake disc

III. BRAKE SYSTEM CALCULATIONS

TABLE II. BRAKE SYSTEM SPECIFICATIONS

\begin{tabular}{|l|l|}
\hline Brake Type & $\begin{array}{l}\text { Single Disc Brake } \\
\text { at the rear axle. }\end{array}$ \\
\hline Brake Fluid & DOT3 \\
\hline Brake Disc Diameter & $200 \mathrm{~mm}$ \\
\hline Master cylinder Diameter & $19.15 \mathrm{~mm}$ \\
\hline Diameter of Piston inside the caliper & $28 \mathrm{~mm}$ \\
\hline Area of Master cylinder & $0.000288 \mathrm{~m}^{2}$ \\
\hline Area of the caliper piston & $0.000615 \mathrm{~m}^{2}$ \\
\hline Coefficient of friction between tire and road & 0.65 \\
\hline Coefficient of friction between Pad and caliper & 0.4 \\
\hline F/R Distribution & $55 \%$ \\
\hline Distance between Front wheel and CG & $0.549 \mathrm{~m}$ \\
\hline Distance between Rear wheel and CG & $0.671 \mathrm{~m}$ \\
\hline
\end{tabular}

A. Mean Effective Radius

Considering uniform wear theory, ${ }^{[5]}$

$$
\begin{aligned}
\mathrm{R}= & \left(\mathrm{r}_{1}+\mathrm{r}_{2}\right) / 2 \\
& =(0.08+0.1) / 2 \\
& =0.09 \mathrm{~m}
\end{aligned}
$$

\section{B. Load Transfer}

$$
\begin{aligned}
& \text { Load Transfer }=(\text { Wah }) /(\lg ) \\
& =(1765.8 \times 2.52 \times 0.259) /(1.22 \times 9.81) \\
& =96.297 \mathrm{~N}
\end{aligned}
$$

$$
\begin{aligned}
& =1765.8 \times 55 \times 100 \\
& =971.19 \mathrm{~N}
\end{aligned}
$$

Static load at Rear axle,

$\mathrm{R}_{\mathrm{r}}=$ Total weight of kart-Static load at Front axle (4)

$$
\begin{aligned}
& =1765.8-971.19 \\
& =794.61 \mathrm{~N}
\end{aligned}
$$

D. Dynamic analysis

Normal Force on Front Wheel,

$\mathrm{F}_{\mathrm{NF}}=$ Static load at Front - Load Transfer

$$
\begin{aligned}
& =971.19-96.29 \\
& =874.9 \mathrm{~N}
\end{aligned}
$$

Normal Force on rear wheel,

$\mathrm{F}_{\mathrm{NR}}=$ Static load at Rear Wheel + Load Transfer

$$
\begin{aligned}
& =794.61+96.297 \\
& =890.9 \mathrm{~N}
\end{aligned}
$$

E. Deceleration

$$
\begin{aligned}
\mathrm{a}= & \operatorname{mg}(\mathrm{L}-\mathrm{r}) /(\mathrm{L}+\mu \mathrm{h}) \\
& =0.65 \times 9.81(1.22-0.473) /(1.22+(0.65 \times 0.259)) \\
& =2.52 \mathrm{~m} / \mathrm{s}^{2}
\end{aligned}
$$

F. Force exerted by Caliper on Disc

$$
\begin{aligned}
\mathrm{F}_{\mathrm{FCP}} & =\left[(\mathrm{FNR} / \mu) \times \mathrm{R}_{\text {disc }}\right] / \mathrm{R}_{\text {mean }} \\
& =(890.9 \times 0.65 \times 0.1) / 0.09 \\
& =643.43 \mathrm{~N}
\end{aligned}
$$

G. Force offered by Caliper on Piston

$$
\begin{aligned}
\mathrm{F}_{\text {caliper }} & =\mathrm{F}_{\mathrm{FCP}} / \mu \\
& =643.43 / 0.4 \\
& =1608.19 \mathrm{~N}
\end{aligned}
$$

H. Pressure on piston $\left(P_{R}\right)$

$$
\begin{aligned}
\mathrm{P}_{\mathrm{R}} & =\mathrm{F}_{\text {caliper }} /\left(2 \times \mathrm{A}_{\mathrm{cp}}\right) \\
& =(1608.19) /(2 \times 0.000615) \\
& =1.307 \times 10^{6} \mathrm{~N} / \mathrm{m}^{2}
\end{aligned}
$$

I. Brake Torque

$$
\begin{aligned}
\mathrm{T}=\mathrm{F}_{\mathrm{NR}} \times \mu \times \mathrm{R}_{\text {disc }} \\
=890.9 \times 0.65 \times 0.1 \\
=57.91 \mathrm{Nm}
\end{aligned}
$$

\section{J. Force on Master Cylinder}

$$
\begin{aligned}
\mathrm{F}_{\mathrm{mc}}= & \mathrm{P}_{\mathrm{R}} \times \mathrm{A}_{\mathrm{mc}} \\
& =\left(1.307 \times 10^{6}\right) \times 0.000288 \\
& =376.23 \mathrm{~N}
\end{aligned}
$$

K. Force on Pedal

$$
\begin{aligned}
\mathrm{Fp}= & \mathrm{F}_{\mathrm{mc}} \times\left(\mathrm{B}_{\text {pedal distance }} / \mathrm{A}_{\text {pedal distance }}\right) \\
& =376.23(0.02 / 0.15)
\end{aligned}
$$




$$
=50.165 \mathrm{~N}
$$

\section{Thermal Analysis}

Energy distribution equation

$\mathrm{KE}=$ Heat loss + Friction loss + work done

M. Heat loss Time

Heat loss $=$ Force exerted by caliper disc $\times$ Velocity $\times$

$$
\begin{aligned}
\text { Velocity } & =\left(\mathrm{V}_{\text {wheel }} \times \mathrm{R}_{\text {mean effective }}\right) / \mathrm{R}_{\text {wheel }} \\
& =(16.67 \times 0.09) / 0.1397 \\
& =10.74 \mathrm{~m} / \mathrm{s} \\
= & 643.43 \times 10.74 \times \mathrm{t} \\
= & 6910.549 \times \mathrm{t} \text { Joules }
\end{aligned}
$$

N. Friction Loss

Friction Loss $=$ Force $\times \mu \times V_{\text {wheel }} \times$ time

$$
\begin{aligned}
& =180 \times 9.81 \times 0.65 \times 16.67 \times \mathrm{t} \\
& =19133.3 \times \mathrm{t} \text { Joules }
\end{aligned}
$$

O. Work done

Work done $=$ Force Displacement $(\mathrm{s})$

$$
\begin{aligned}
& =(\mathrm{m} \times \mathrm{a}) \times \mathrm{s} \\
& \quad\left(\mathrm{s}=\mathrm{u} \times \mathrm{t}-(1 / 2) \mathrm{at}^{2}\right) \\
& =180 \times 2.52 \mathrm{u} \times \mathrm{t}-(1 / 2) \mathrm{at}^{2} \\
& =\left(7561.5 \mathrm{t}-2224.91 \mathrm{t}^{2}\right) \text { Joules }
\end{aligned}
$$

P. Kinetic Energy

Kinetic Energy $=(1 / 2) \times m v^{2}$

Where,

$\mathrm{m}=$ mass of the vehicle $(\mathrm{kg})$

$\mathrm{v}=$ velocity of the vehicle $(\mathrm{m} / \mathrm{s})$

$$
\begin{aligned}
& =\left((1 / 2) \times 180 \times 16.67^{2}\right) \\
& =25010 \text { Joules }
\end{aligned}
$$

On substituting equation (14)

$$
\begin{aligned}
& 25010=6910.454 \mathrm{t}+19133.3 \mathrm{t}+7561.5 \mathrm{t}-2224.91 \mathrm{t}^{2} \\
& 25010=33603.284 \mathrm{t}-2224.91 \mathrm{t}^{2} \\
& \mathrm{t}=0.785 \mathrm{sec} \\
& \begin{aligned}
& \text { Q. Stopping distance }(S) \\
& \mathrm{S}=((\mathrm{u}+\mathrm{v}) / 2) \times \mathrm{t}) \\
& \quad {[(16.67+0) / 2] \times 0.785 }
\end{aligned}
\end{aligned}
$$

$$
=6.5 \text { Meters }
$$

R. Rubbing Area on one side of disc

Rubbing Area on one side of disc $=\pi / 4\left(\mathrm{D}^{2}-\mathrm{d}^{2}\right)$

$$
\begin{aligned}
& =\pi / 4\left(200^{2}-152^{2}\right) \\
& =13270.08737 \mathrm{~mm}^{2}
\end{aligned}
$$

\section{S. Total Rubbing Area on Brake of disc}

Total Rubbing Area on Brake of disc = Rubbing Area on one side of disc $\times 2$

$$
\begin{aligned}
& =13270.08737 \times 2 \mathrm{~mm}^{2} \\
& =26540.17474 \mathrm{~mm}^{2}
\end{aligned}
$$

\section{T. Heat Flux $(q)$}

$\mathrm{q}=$ Brake Power / Total Rubbing Area on Brake of disc

Brake Power $=($ Kinetic Energy $\times$ Weight Distribution $) /$ Brake Time

$$
\begin{aligned}
& v=u+a t \\
& 0=16.67+2.52 \mathrm{t} \\
& \mathrm{t}=6.615 \mathrm{sec}
\end{aligned}
$$

Brake Power $=25010 \times 0.45 \times 6.615$

$$
=1701.34 \text { Watts }
$$

$$
\mathrm{q}=1701.34 / 0.03
$$$$
q=56743 w / m^{2}
$$

\section{MODELS DESIGNED FOR CASE-STUDY}

Three models were designed in SolidWorks for the analysis of the brake rotor. All the models have the same outer diameter and mounting geometries. The profile and air vent holes are changed in the three models. The models given below are used for the static structural and steady state thermal analysis.
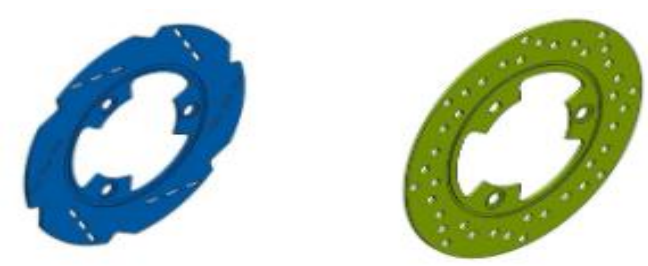

Model 1

Model 2 


\section{MESHED MODELS}

All three models are meshed in Ansys with tetrahedron elements with following criteria.

\section{TABLE III. MESH QUALITY CRITERIA}

\begin{tabular}{|l|l|}
\hline Sizing & Tetrahedrons \\
\hline Element type & $1 \mathrm{~mm}$ \\
\hline Element size & Active assembly \\
\hline Initial size seed & Medium \\
\hline Smoothing & Fast \\
\hline Transition & \\
\hline
\end{tabular}

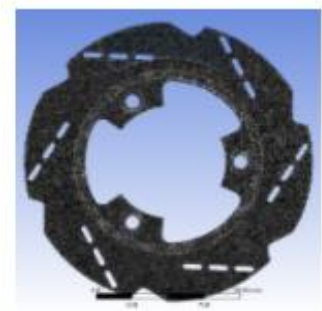

Model 1

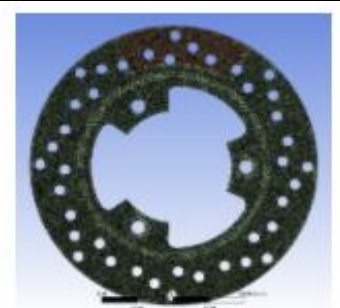

Model 2

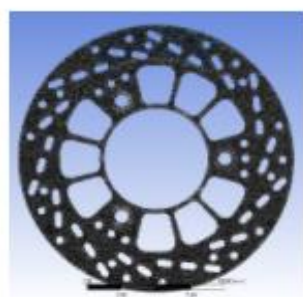

Model 3

Fig. 2. Models of meshed brake disc

TABLE IV. NUMBER OF NODES AND ELEMENTS

\begin{tabular}{|c|l|l|}
\hline Model & Number of Nodes & Number of Elements \\
\hline 1 & 604598 & 384568 \\
\hline 2 & 602916 & 385715 \\
\hline 3 & 494599 & 314969 \\
\hline
\end{tabular}

\section{STATIC STRUCTURAL ANALYSIS}

From the calculations, force exerted on the disc by the brake pad is found to be $643 \mathrm{~N}$ on both sides. AluminiumMetal Matrix Composite (AMC) is the best material for brake disc rotor, due to economic feasibility Grey Cast Iron was selected. ${ }^{[2]}$ The brake pad dimensions are measured and the profile is drawn on the disc surfaces. Three mountings of the disc are made as fixed support and the force is applied on the pad contact surface and structural analysis is carried out. Deformation and stress induced in the disc are found for all three models. Sample results of one model for each analysis is attached and the comparison table is given.

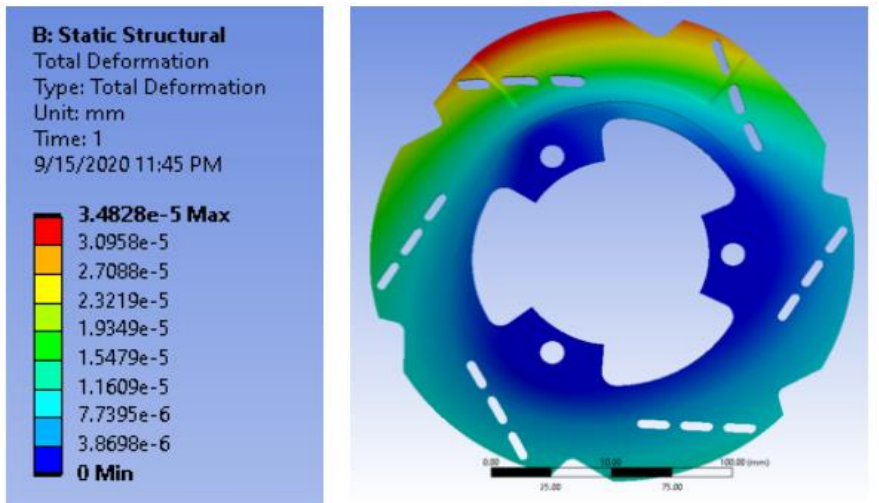

Fig 3. Total Deformation of model 1

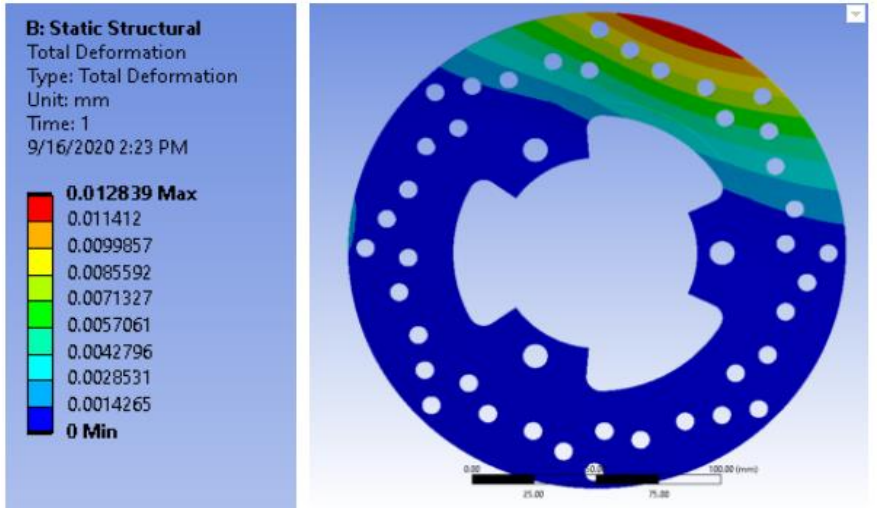

Fig 4. Equivalent stress for model 2

\section{STEADY STATE THERMAL ANALYSIS}

From the calculation heat flux produced is found to be $56743 \mathrm{w} / \mathrm{m}^{2}$, this value is given as a heat source to the pad surface and material properties of grey cast iron is selected and analysis is carried out to find temperature distribution in the brake disc.
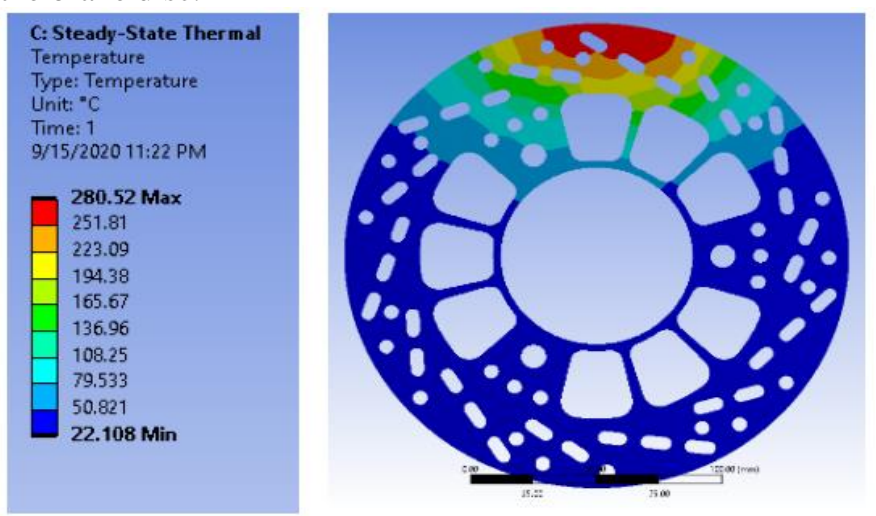

Fig 5. Temperature distribution for model 3

VIII. COMPARISON OF STEADY STATE ANALYSIS

TABLE V. COMPARISON OF RESULTS

\begin{tabular}{|c|c|c|c|c|c|c|}
\hline \multirow{3}{*}{ Results } & \multicolumn{4}{|c|}{ Static Structural } & \multicolumn{2}{c|}{$\begin{array}{c}\text { Steady State } \\
\text { Thermal }\end{array}$} \\
\cline { 2 - 7 } & $\begin{array}{c}\text { Total } \\
\text { Deformation } \\
(\mathbf{m m})\end{array}$ & $\begin{array}{c}\text { Equivalent Stress } \\
(\text { MPa })\end{array}$ & $\begin{array}{c}\text { Temperature } \\
\text { Distribution }\left({ }^{\circ} \mathbf{C}\right)\end{array}$ \\
\cline { 2 - 7 } & Min & Max & Min & Max & Min & Max \\
\hline Model 1 & 0 & $3.8 \times 10^{-5}$ & $2.1 \times 10^{-6}$ & 0.2097 & 22 & 255 \\
\hline Model 2 & 0 & 0.0128 & 0.000257 & 2.146 & 22 & 282 \\
\hline Model 3 & 0 & 0.0007 & $2.7 \times 10^{-5}$ & 0.23172 & 22 & 280 \\
\hline
\end{tabular}


From the analysis it is found that, Model 1 has minimum stress, deformation and temperature rise, hence it is selected for the CFD analysis to implement the real time conditions such as air flow.

\section{CFD ANALYSIS}

The Analysis is carried out by using the Ansys Fluent 2019 for Model 1. The procedure followed and inputs given for the CFD Analysis is given below,

The brake disc is modelled in solidworks and imported to Ansys fluent. Using Spaceclaim the pad surface is sketched over the disc outer surface; this will help to give the energy input to the body (Heat flux).

Rotating domain, a cylindrical portion around the disc is created, since the air molecules very close to the disc will rotate due to the rotating velocity of the disc.

Air flow domain, a rectangular domain is created to give the input and output velocity of the air over the closed surface, this air flow is due to the vehicle motion. Thus, the Rotating and Air flow domain are designed and naming is done in spaceclaim.

Meshing is done with Tetrahedron elements, since it provides accurate results for small domain CFD analysis, inflation is given to create the boundary layer effect in the immediate air contact region and Mesh size of $1 \mathrm{~mm}$ is provided for the disc to make conduction feasible. The setup file is launched and mesh quality is checked. Pressure based method is selected. Since, the Mach Number is lesser than 0.3 hence the flow is incompressible.

Steady state analysis with the K-Epsilon turbulent model is selected, since it gives more accurate results for heat calculations.

The material properties of grey cast iron are updated, and material is specified for the disc and air domain. The heat flux $\left(\mathrm{W} / \mathrm{m}^{2}\right)$ is given to the pad surface, since it is the heat source. The air inlet velocity for the air flow domain and rotational velocity for the rotating domain is given. On solving the simulation, the maximum temperature rise in the disc is found to be $547 \mathrm{~K}$, which is lesser than the recrystallisation temperature of grey cast iron is around 723 $\mathrm{k}$, hence our disc is safe

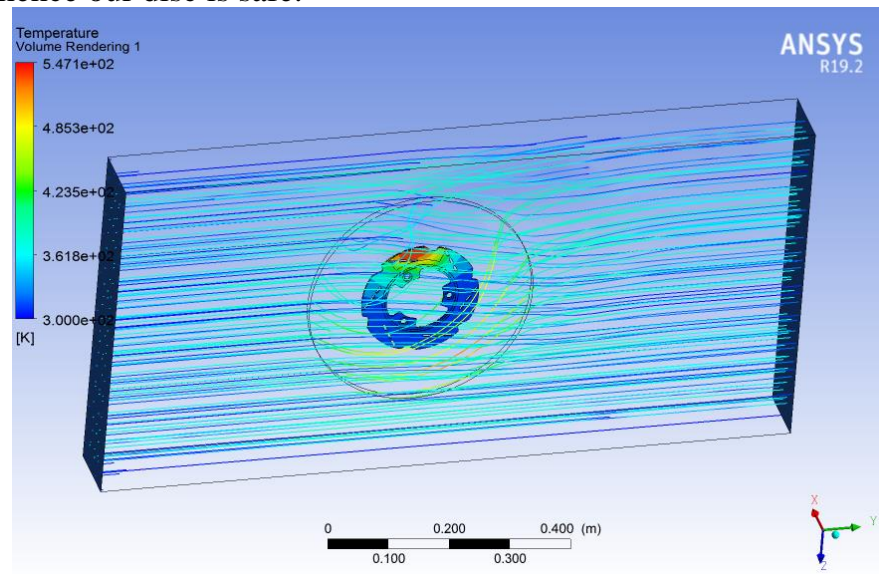

Fig 6. Ansys Fluent Result

\section{STATIC STRUCTURAL ANALYSIS OF BRAKE PEDAL AND HUB}

Since the brake pedal and the hub are manufactured, its factor of safety has to be ensured. Hence structural analysis is carried out for these two components.

\section{A. Brake Pedal:}

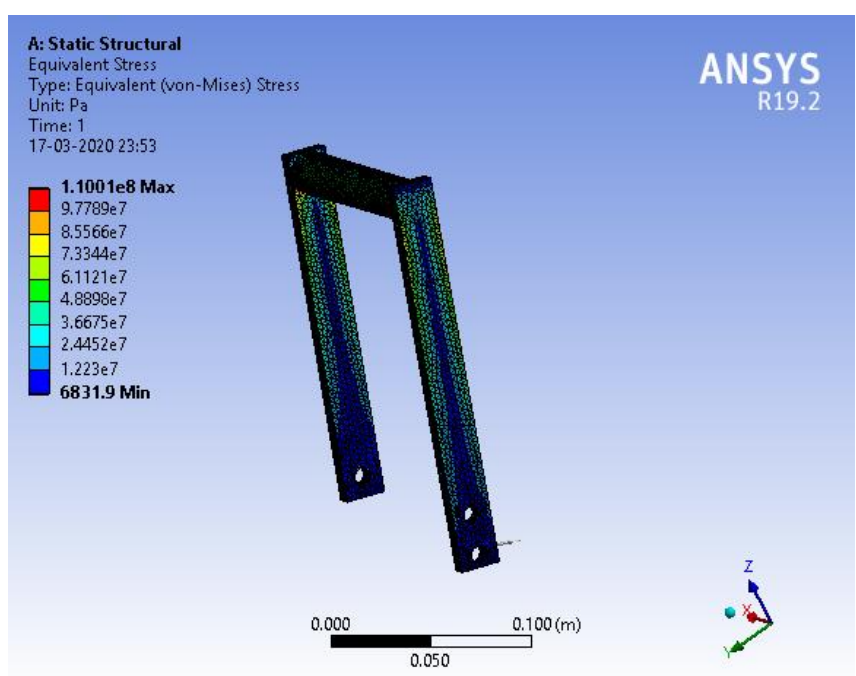

Fig 7. Static structural analysis of Brake Pedal

Since we know the applied force by the driver and force resisted by the master cylinder, these two force values are given as an input and the fulcrum point is made as fixed support. Material is chosen as mild steel and analysis is carried out. From the study it is found that the stress induced in Brake Pedal is $110 \mathrm{MPa}$ which is lesser than yield stress (250 Mpa). Hence the safety of the brake pedal is ensured.

\section{B. Brake Disc Hub:}

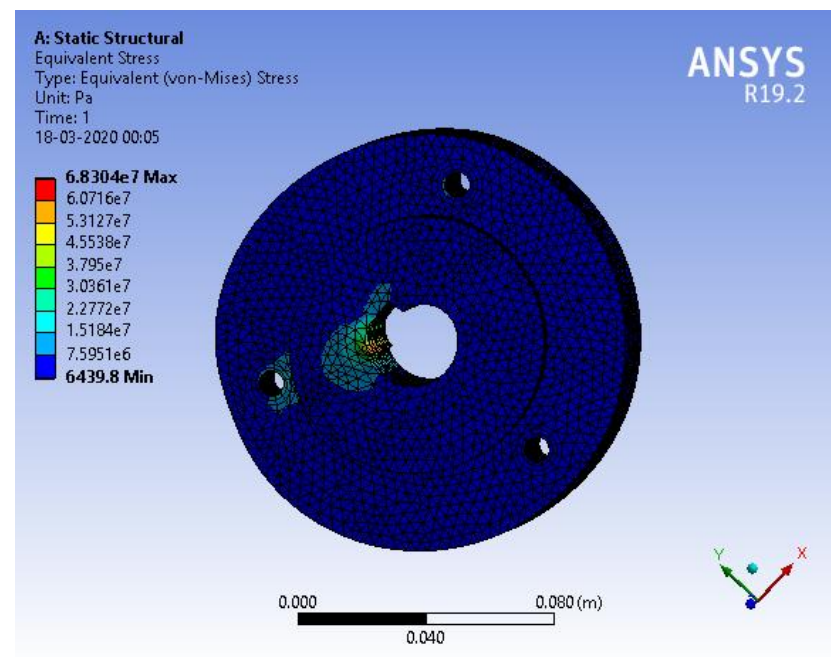

Fig 8. Static structural analysis of Brake Disc Hub

Brake disc hub is a connector between the brake disc and the rear axle, material is selected as aluminium due to its light weight property. The mounting points of the brake disc are made as fixed support and brake torque is given as moment input on one side of the key hole. On performing the analysis, 
the stress induced is found to be $68 \mathrm{MPa}$ which is lesser than yield stress (276 Mpa). Thus, the design safety of the brake hub is ensured.

\section{CONCLUSION}

The design calculations are done to find the force acting on the disc while braking, various brake disc profiles are designed in SolidWorks and stress analysis, deformation analysis and temperature distribution are analysed in Ansys. From the analysis a best disc (Model 1) profile is selected and CFD Analysis is performed to check the temperature rise in the disc in real time scenario. From the study, the temperature rise value of the disc is lesser than the recrystallisation temperature hence our disc is safe and the results obtained by the study goes hand in hand with real time experiment.

\section{REFERENCES}

[1] Anjul Chauhan, Lalit Naagar 'Design and Analysis of a Go-Kart' International Journal of Aerospace and Mechanical Engineering Volume 3 - No.5, September 2016

[2] Swapnil R. Umale, Dheeraj Varma 'Analysis and Optimization of Disc Brake Rotor'-International Research Journal of Engineering and Technology (IRJET) Vol:03 Issues:11 Nov-2016.

[3] M.A. Maleque, S. Dyuti and M.M. Rahman (Member, IAENG) 'Material Selection Method in Design of Automotive Brake Disc' - Proceedings of the World Congress on Engineering 2010 Vol III.

[4] 'Fundamentals of Vehicle Dynamics' by Thomas D. Gillespie

[5] 'Theory of Machines Book' by J.K. Gupta and R.S. Khurmi

[6] 'Engineering Heat and Mass Transfer' by RC Sachdeva 